I Centre de Socilogie Européenne, École des Hautes Études en Sciences

Sociales (EHESS), Paris, France

garciaparpet@gmail.com

https://orcid.org/oooo-oooI-5700-5783

Marie France Garcia Parpet ${ }^{\prime}$

\title{
MERCADOS E PRAÇAS DE MERCADO: KARL POLANYI E O CAPITALISMO CONTEMPORÂNEO
}

Neste artigo exploramos distinções conceituais, concebidas por Karl Polanyi, entre mercado, sistema de mercados formadores de preços e praça de mercado, para mostrar como podem ser úteis para pesquisas atuais sobre a evolução do capitalismo, particularmente, as que estudam salões de exposição e plataformas digitais. ${ }^{\mathrm{I}}$ Num primeiro momento, evocamos, de maneira breve, a contribuição de Polanyi para repensar o conceito de mercado tal como manipulado pela literatura econômica, ao operar a distinção entre os conceitos de praça de mercado e mercado formador de preço, assim como seu esforço em A grande transformação (Polanyi, I983) para colocar em evidência a historicidade do sistema de mercados formadores de preço (também denominado sistema capitalista por outros autores), apoiando-se em trabalhos de antropologia social e de história. Em seguida, exploramos a ideia de que o conceito de praça de mercado não é apenas útil para a análise das sociedades primitivas ou camponesas, mas é também pertinente para analisar o sistema capitalista contemporâneo e seus desdobramentos. Com esse intuito, recorremos a trabalhos etnográficos e/ou sociológicos, sobre praças de mercado do mundo contemporâneo, selecionados no decorrer de uma trajetória de pesquisa empírica e bibliográfica. ${ }^{2}$ Entre os efeitos múltiplos que podem ser observados por meio da literatura, veremos como a praça de mercado pode ser criadora de valor, especialmente simbólico, mas também material, assim como pode estar na origem de nova diferenciação social. Assim, o conceito de praças de mercado pode contribuir para o estudo da evolução dos sistemas de mercado na era da mundialização. 
As preocupações de Polanyi com os efeitos nefastos do sistema de mercados formadores de preço (mercados capitalistas) sobre a democracia perpassam sua obra como um todo. Em A grande transformação (Polanyi, I983), ele mostrou como a economia, organizando-se inteiramente à base de mercados interconectados, a partir do século XIX, tendeu a separar-se das outras instituições sociais que a controlavam, para tornar-se instituição dominante, supostamente autorregulável. Paralelamente a publicações de cunho mais político, tais como Our obsolete market mentality (Polanyi, I968) empreendeu um trabalho de pesquisa sobre a gênese da economia e do sistema de mercados que marcou o pensamento das ciências sociais contemporâneas. Recrutado pela Universidade de Columbia, New York, em 1947, junto com Conrad Arensberg, ele se debruçou sobre as sociedades primitivas, em busca de outras formas de inscrição de mercados na organização social e de outros modos de circulação de bens e serviços diferentes dos mercantis (reciprocidade, redistribuição etc.). Fixou um programa de pesquisa sobre as origens das instituições econômicas, que se somou às suas reflexões a partir de Bronislaw Malinowski e Richard Thurnwald, e o levou à formulação de que a economia não existe, separadamente, como sistema nessas organizações sociais, mas "imbricada" (embedded no original) em outras instituições: parentesco, religião, sistema político etc. Um grupo composto por antropólogos, historiadores da antiguidade, sociólogos e economistas trabalhou na crítica da teoria econômica, na construção de tipologias de sistemas econômicos, em especial sobre o mercado e o uso da moeda. Esses trabalhos, reunidos sob o título Trade and market in the early empires: economies in history and theory (Polanyi, I957) trouxeram, a partir dos exemplos empíricos estudados, uma nova definição da economia, que demonstra ser a existência do econômico sob forma de instituições separadas e independentes das demais uma exceção histórica, de maneira alguma algo intrínseco à natureza humana. O "sistema de mercados autorregulável", suposto pelos economistas, é uma construção histórica que presumiu a performatividade das teorias elaboradas pelos especialistas dessa disciplina (MacKenzie, Muniesa \& Siu, 2007). Trade and market esteve na origem de um grande debate entre seus seguidores, nomeados substantivistas, e seus opositores, ditos formalistas - estes últimos buscando preservar a universalidade do domínio econômico, considerada pelos adeptos dos economistas neoclássicos - com concepções retomadas por certos cientistas sociais, como Talcott Parsons, que lhe enviou manuscritos de Economy and society (Parsons \& Smelser, I956) ainda inétido, a quem Polanyi (I957) agradece, na Introdução ao livro, que apresenta dois de seus capítulos voltados para o debate com o mais influente sociólogo norte-americano na época. Scott Cook (I966), na prestigiosa American Anthropologist, dá início ao longo e denso debate em "antropologia econômica", que implicou artigos em revista, coletâneas de ambas as escolas de pensamento e etnografias adeptas de uma ou de outra posição teórica. Diversidade de sistemas econômicos, no tempo e no espaço, contra unicidade dos modos de existência da atividade econômica; 
caráter histórico dos conceitos adequados à economia capitalista, versus caráter universal dos conceitos de economias de mercado; tal é o ponto central das controvérsias em ciências sociais, desde o final dos anos I950.

Os estudos empíricos realizados sobre a Antiguidade e sobre sociedades contemporâneas não ocidentais focalizaram, em grande medida, locais onde trocas mercantis se passavam com regularidade periódica; tais espaços são conceituados como praças de mercado. Essas reuniões repetidas de compradores e vendedores de bens, nas quais ocorrem muitas outras interações, como espetáculos de arte, reuniões políticas, cerimônias religiosas em espaços adjacentes, competições esportivas etc., são distinguidas do conceito de mercado, tal como usado pelos economistas, que supõe o encontro potencial de compradores e vendedores de bens e serviços, unicamente com esse fim, com frequência ocorrendo de forma desterritorializada e provocando flutuação dos preços dos bens trocados. O pressuposto do mercado é que haja uma multiplicidade de indivíduos ou grupos interessados em vender os bens e serviços que possuem, confrontados regularmente com uma multiplicidade de indivíduos ou grupos interessados em adquirir tais mercadorias. Essa atenção particular em direção ao estudo de praças de mercados e das moedas que servem ao intercâmbio dos bens e serviços permitiu a Polanyi mostrar a particularidade dos circuitos restritos de trocas mercantis em determinadas sociedades, que de forma alguma se vinculam a intercâmbios generalizados da quase totalidade dos bens e serviços, como em sociedades capitalistas. A passagem de mercados isolados, e regulados por autoridades específicas, a mercados interconectados, cujos agentes das trocas tomam decisões apenas em função dos interesses econômicos, é processo histórico particular de importância capital. Por isso mesmo é o objeto central do livro A grande transformação, em que o autor analisa como a terra e o trabalho se transformam em mercadorias, provocando a interdependência do conjunto dos mercados existentes. Em capítulo do Trade and market, intitulado "A economia enquanto processo instituído", Polanyi chama atenção para o fato de que, até então, eram os economistas que definiam os problemas sociológicos existentes na esfera da economia, afirmando a universalidade da racionalidade induzida por mercados, definindo a economia de uma maneira formal, como modo de enfrentar problemas de raridade e de maximização de uso dos recursos escassos: uma definição da economia que decorria da observação exclusiva da Europa Ocidental e dos EUA, em época recente, onde existia um sistema de mercados formadores de preço (em que trabalho, moeda e terra viraram mercadorias). A observação atenta de outras sociedades, por historiadores e antropólogos, os confrontava porém com grande variedade de instituições diferentes do mercado para trocas correntes, marcadas pela dominância dos princípios da reciprocidade e da redistribuição, nas quais estavam "imbricados" para regular a produção e a circulação dos meios de subsistência das pessoas. Vemos assim, que os conceitos de praças de mercado, mercado (no sentido de categoria utili- 
zadas pelos agentes contemporâneos) e sistemas de mercados formadores de preço se referem a coisas diferentes, que apontam para configurações sociais com perfil próprio, dando lugar a interações sociais diversificadas e evidenciando que tais conceitos nunca podem ser tomados como sinônimos.

Esses exemplos permitiram perceber que a transformação dos mercados em um sistema autorregulador, dotado de uma potência avassaladora e capaz de desregular e forçar transformações em outros subsistemas sociais, não é o resultado de uma tendência à proliferação espontânea, inerente às praças de mercado, mas antes uma consequência de estimulações administradas ao corpo social por certos agentes, e Polanyi menciona que os princípios do laissez-faire nada tinham de natural. Os mercados livres nunca se teriam expandido se as interações mercantis fossem movidas apenas pelo movimento que determina sua existência. Foram atos políticos que modificaram os modos das interações mercantis e dotaram os mercados da potência que passaram a exibir. Assim, segundo Polanyi (I983: I89), "as manufaturas de algodão na Inglaterra, principal indústria do 'livre comércio', foram criadas com a auxílio de ajudas tarifárias protecionistas, incentivos à exportação, subsídios indiretos aos salários; o próprio laisser-faire foi imposto pelo Estado. [...] O liberal utilitarista vê no governo o grande agente da realização da felicidade".

Ao opor o estudo de praças de mercado, lugar físico em que se encontram com regularidade os comerciantes e sua clientela, como as feiras, em que pessoas se reúnem, ofertando e demandando produtos ou serviços, ao conceito de mercado, modalidade de regulação da transferência de bens de indivíduos (ou grupos, ditos ofertantes) para outros indivíduos (ou grupos, ditos demandantes) por meio da flutuação dos preços, que não precisa se materializar em um espaço físico apenas, tal autor abriu a possibilidade de estudar, etnograficamente, praças de mercado existentes em sociedades não ocidentais na África (Bohannan, Dalton, I962; Piault, I97I), mas também na própria sociedade capitalista, nos países europeus (de La Pradelle,I996), na Ásia (Skinner, I964) e na América Latina (1957). Karl Polanyi nunca se dedicou a estudos de praças de mercado no sistema capitalista; sua preocupação era enunciar o caráter histórico do mercado autorregulador e denunciar seus efeitos perversos. A análise das praças de mercado, das sociedades ditas primitivas ou de épocas mais remotas, era uma maneira de mostrar a peculiaridade do lugar da economia e do mercado em nossa sociedade, e também que essas configurações sociais não podiam ser tomadas como um embrião do sistema de mercados, que nelas teria apenas seu ponto inicial e passageiro. No entanto, para Polanyi (I957: I89), o mercado autorregulador não deixa de se realizar em condições muito concretas: "O laissez-faire nada tem de natural, os mercados livres não poderiam ter aparecido se as coisas tivessem ficado iguais a si mesmas". A dominância do sistema econômico pelos mercados, todavia, tem efeitos irresistíveis sobre a organização inteira da sociedade: a sociedade passa a existir como apêndice 
de mercados. Em vez de a economia estar imbricada nas relações sociais, são as relações sociais que estão imbricadas no sistema econômico, e os outros domínios sociais se tornam subordinados aos movimentos do mercado; isso não impede que a sociedade tente resistir ao sistema de mercado, como se observa na transferência de órgãos humanos, em operações cirúrgicas, concebidos com "dons", mas nunca como operações de compra e venda (Steiner, 2010), uma vez que as transações têm materialidade, por mais que sejam pensadas como algo abstrato. Essa materialidade das relações mercantis não escapou a Polanyi quando ele menciona os regulamentos que facilitaram a instalação do mercado autorregulável e os combates que acompanham o desenvolvimento do mercado. ${ }^{3} \mathrm{Se}$, para os economistas, o mercado é um mecanismo abstrato no qual oferta e demanda se confrontam por meio de flutuação de preços, nosso autor se preocupa em compreender as condições concretas que permitem essa confrontação entre a oferta e a demanda, e seu ajustamento mútuo mediante transações com flutuação de preços. A evidência atual da existência material dos modos de operar da lei da oferta e da procura não deve impedir o entendimento da maneira como pessoas e bens se tornam parte integrante da curva da oferta e como pessoas dispondo de meios de troca se agrupam na curva da demanda para os adquirir.

\section{PRAÇAS DE MERCADO: FORMAS REMANESCENTES DE UNIVERSOS TRADICIONAIS?}

Formatada segundo o paradigma do mercado autorregulável, a sociedade de mercado é muitas vezes vista como não precisando de praças de mercado, conhecendo outras formas de distribuição que parecem, aos olhos de alguns, melhor satisfazer suas exigências de rentabilidade e de racionalidade. Segundo Michèle de la Pradelle (I996: I I), "É em virtude de um economicismo muitas vezes implícito que somente as praças de mercado exóticas ou arcaicas podiam ser objeto de etnografia (como se a etnografia não pudesse ser útil para estudo da economia)". Dessa forma, uma vez que se generalizou a extensão do mercado, as praças de mercado constituem cada vez menos objetos de pesquisa tidos como pertinentes. Ora, as praças de mercado não existem apenas como formas remanescentes de universos tradicionais nem como instituições que pretendem resistir ao capitalismo, como no caso das praças de mercado alternativas, analisadas por Paul Albinsson e Yasanti Perera (2012), no sul dos EUA, no começo do século. Longe de ser abandonadas em ambientes capitalistas, elas tendem a se multiplicar e a se diversificar, com o decorrer do tempo e, sobretudo, na atualidade, haja vista a criação, permanência e centralidade de bolsas de valores (Hassoun, 2000a, 200ob; Müller, 2006; Muniesa, 2007). As feiras em que se abastece a população para a vida quotidiana não deixaram de existir, nem na capital francesa (Lallement, 2010). No Paraguai diferenças de tributação estão na origem de uma vasta praça de mercado na fronteira com o Brasil (Rabossi, 
2004). Na Europa, os leilões decrescentes para a venda de frutas, legumes e gado foram criados para se contrapor ao predomínio de relações pessoais durante as trocas e se aproximar do paradigma de mercado como mecanismo impessoal, como o imaginam os economistas (Bousquet, I969; Vaudois, I985 Garcia Parpet, 2003). Se as feiras são particularmente numerosas para os bens artísticos (Moulin, I992; Quemin, I994; Bueno, 2005), elas existem também para outros bens, tais como automóveis, móveis, aviões, turismo etc. (Pulman, 20I9) e tecnologias de gestão (Piçanco, 20I8). Na França, no Brasil, na Turquia, nos EUA, as feiras, salões ou festivais para promoção de um produto particular se multiplicaram: por exemplo, no Brasil, as feiras ou salões de cerveja (Krohn, 20I7) e de gado (Leal, 2008). Feiras e salões de exposição de vinho, filmes e livros mostram que esses eventos podem ser decisivos no entendimento da expansão, criação e recomposição de mercados globalizados (Garcia Parpet, Leclerc \& Sorá, 20I5). Símbolos da modernidade, enfim, as praças de mercado digitais (plataformas), por sua vez, se desenvolvem, segundo Ursula Huws (20I6), a um ritmo exponencial, mundo afora. Brisset e Naegelen (2008) mostram assim a evolução fulgurante de E-bay. Plataformas generalistas propõem produtos não virtuais, tais como serviços de realização de compras, de baby-sitting e outros pequenos trabalhos que não requerem formação específica (a exemplo do TaskRabbit, que tem filiais em vários países), ou produtos virtuais, como design gráfico, programação informática e duplicação de dados, que se desenvolvem, independentemente da localização geográfica dos ofertantes e demandantes e, por isso mesmo, têm muitas vezes envergadura mundial (Casilli, 20I7). Ou, ainda, o Google, que aparentemente nada apresenta para vender, mas recolhe inúmeros dados que se tornam objeto de transação posterior.

Essas praças de mercado têm efeitos sui generis e, portanto, sua análise é indispensável, em contraponto ao conceito de mercado, no sentido assumido pelos economistas mainstream, ou seja, um mecanismo abstrato em que, por meio da flutuação de preços, oferta e demanda se confrontam e se ajustam. Esses tipos de concentrações da oferta e da demanda em espaços específicos não são neutros do ponto de vista das transações, da criação de valor dos produtos, das relações sociais envolvidas entre os agentes, das categorias sociais que participam das trocas e, em consequência, da repartição dos ganhos materiais e simbólicos decorrentes desses intercâmbios. A existência dessas praças de mercado supõe a competição com outras instituições, também dedicadas a trocas mercantis, como, por exemplo, supermercados, cooperativas, vendas na propriedade etc. Os diferentes circuitos de trocas mercantis e os agentes que participam de cada um deles também estão em concorrência, para drenar participantes e intercâmbios concretos. Não custa lembrar que há competição entre produtores para vender seus produtos, mas há também competição no nível da institucionalização das relações mercantis (Bourdieu, I997b) que, por sua vez, é o resultado de uma competição entre grupos sociais, mas também 
entre concepções da economia e dos mercados, que tentam se impor de forma performática às relações mercantis (Garcia Parpet, I996; Callon, I998; Mackenzie, Muniesa \& Siu, 2007; Paranthoën, 20I5). Mediante as disputas sobre as redes de mercado, concebidas como mais eficientes, travam-se os combates pela recomposição das instituições sociais como um todo e de seu caráter duradouro ou efêmero.

\section{PRAÇAS DE MERCADO E CRIAÇÃO DE VALOR}

O valor dos produtos culturais tem realidade dupla, mercadoria por um lado, com preço de compra e venda, e significações por outro, o que explica o fato de o valor propriamente simbólico e o valor mercantil ficarem relativamente independentes. As instituições e os dispositivos aparentemente destinados ao julgamento e à circulação dos produtos fazem parte integrante do aparelho de produção que deve assegurar a crença no valor dos produtos (Bourdieu, I977a). Como afirma Arjun Appadurai (I986, p. 2), o valor nunca é inerente às propriedades dos objetos, mas é julgamento dos indivíduos a respeito dos objetos. A feira de Carpentras, analisada por Michèle de la Pradelle (I996: 2 I I), é reveladora do efeito praça de mercado, que "faz a mercadoria": a autora mostra que, nessa cidade do sul da França, são vendidos produtos que podem ser encontrados em todos os supermercados da região, mas que "na feira se passa algo mais do que compra". A feira oferece uma sociabilidade sui generis, uma mistura social, em que as distinções sociais são colocadas entre parênteses. Em volta de cada banca de venda instaura-se "uma microsociedade - cujos atores coexistem como numa multidão, mas entram em relação... e é uma combinação de situação de anonimato e interação entre sujeitos, que se reconhecem como iguais - que faz da feira um espaço público" (Pradelle, I 996: 283). Limitando-se à troca de lugares-comuns, consegue-se uma base de entendimento. É essa sociabilidade que, junto com o regateio, reconfigura os produtos e faz com que as azeitonas, por exemplo, um produto local, sejam preferidas às do supermercado. Enquanto outrora as feiras se opunham ao pequeno comércio estabelecido, "A feira é uma produção coletiva de anacronismo, e por isso mesmo corresponde a uma lógica contemporânea, entrando assim em competição com supermercado" (Pradelle, I996, p. 359). Dito de outra maneira, os produtos vendidos na feira adquirem nova qualificação, pelo fato de ser vendidos num lugar referido ao passado e, portanto, ser objeto de uma certa patrimonialização, como ressaltaram Luc Boltanski e Arnaud Esquerre (2017), analisando essa nova forma de capitalismo.

Constituindo outra configuração de praças de mercados, os leilões ascendentes acentuam a dimensão de mercadoria dos objetos, de tal maneira, que os preços fixados podem ser considerados inapropriados em outros contextos. Assim, Arjun Appadurai (I986) nota que os preços podem aumentar demasiadamente em um leilão de arte. Alain Quemin (I994: 52), por sua vez, mostra que os leilões, como o de Drouot-Nord, em Paris, 
longe de ser um espaço desmaterializado onde se pode materializar a concorrência pura e perfeita, na prática fazem com que o lugar da venda dependa das características do produto, e, em parte, ele as condiciona. As características dos produtos dispersos podem revelar-se progressivamente no decorrer da interação que constitui o leilão.

O autor mostra que o valor de um objeto não tem a ver só com suas características, mas também remete ao status do comprador e ao local dos leilões em que são negociados os objetos: a sala Drouot-Richelieu é destinada a móveis e objetos que constituem a mobília de interiores burgueses e que chegam, às vezes, a ser objetos de arte; a sala Drouot-Montaigne é, claramente, destinada a objetos de arte; e a sala Drouot-Nord, a produtos de uso comum, em meio aos quais, entretanto, pode haver produtos de categoria mais distinta. Os comissários não são simples árbitros entre os vários ofertantes e demandantes, mas eles classificam os objetos para ser comercializados em leilões diferentes, uma classificação que, em si, contribui para as variações de valor. Quemin mostra ainda que a posição do objeto na ocasião da venda faz variar o valor: em geral, a venda "esquenta" mais entre a metade da transação e seu final, e retorna a um clima mais fraco nos últimos momentos.

Os leilões descendentes, por sua vez, que se desenvolveram na Europa para comercialização das flores, frutas e legumes no período pós-guerra (Vaudois, I980, I985), foram estimulados pelas instituições científicas e governamentais para viabilizar uma confrontação da oferta e da demanda, o que daria mais transparência às transações, tradicionalmente impregnadas de relações pessoais. A análise etnográfica do leilão de morangos em Fontaines-en-Sologne permitiu objetivar relações de força entre os produtores e, ao mesmo tempo, reconfigurá-las, assim como houve modificação das estratégias dos diferentes agentes participantes (Garcia Parpet, 2003). O modo de institucionalização da venda dos morangos modificou-lhes o estatuto e o de seus produtores. Graças a esse modo de comercialização, as frutas adquiriram um selo de qualidade e notoriedade regional. A exposição das mercadorias de diferentes produtores, umas ao lado das outras antes de iniciar o leilão de preços, está na origem de preços diferenciais, durante a realização das vendas. A transparência exigida pelos ofertantes fez com que os produtores fossem confrontados com produtos de mais qualidade e tivessem forte estímulo para melhorar a de seus próprios produtos, e os preços, até ali inferiores à média nacional, passaram a ser nitidamente superiores, com a entrada, em funcionamento regular, do mercado computadorizado de Fontaines-en-Sologne.

Assiste-se, também, ao crescimento dessas praças de mercado de produtos específicos, de feiras ou salões de exposição, a distinção do termo sendo relevante:4 Bertrand Pulman (2019) menciona a existência de 450 salões internacionais, e somente em Paris podem ser citados, por exemplo, o salão de jogos eletrônicos, que reúne 300 mil pessoas, e o de automóveis, que recebe mais de 
um milhão de visitantes por ano. Parte significativa do comércio internacional passa por essas manifestações, que atraem profissionais do mundo inteiro. Invisíveis nos dados agregados das trocas internacionais e das análises do comércio internacional dos economistas, as feiras têm, no entanto, um papel crescente na internacionalização dos mercados. Os bens simbólicos não são exceção, e, a partir do caso dos filmes e programas audiovisuais, dos livros e dos vinhos estudados por Garcia Parpet, Leclerc e Sorá (20I5), veremos que as feiras contribuem para objetivar a relação de força em níveis internacional, nacional ou mesmo regional e, ao mesmo tempo, para reconfigurar e modificar as estratégias dos diferentes agentes que delas participam. Assim, no mundo da literatura, a Feira de Frankfurt ocupa indiscutível lugar central na apreciação das obras, assim como Cannes o faz para o mercado de filmes.

Elas objetivam a competição de alta qualidade, em dado momento do tempo, e contribuem para que se visualizem as formas de valorização simbólica dos bens, das quais depende frequentemente a flutuação dos preços. Elas cons tituem megaeventos de periodicidade regular, rituais que reúnem profissionais de um bem particular (importadores, negociantes, publicitários etc.) e, ao mesmo tempo, lugares de troca de informações e de sociabilidade, assim como de competição simbólica entre os participantes, torneios de valor, para empregar a expressão de Igor Kopytoff (I986). Nesses locais reelaboram-se, de maneira constante, novas hierarquias de valores pelo viés de exposição de produtos, de concursos, de conferências e de debates, que têm consequências econômicas. Como nas coleções de moda (Bourdieu, I975), as praças de mercado internacionais constituem eventos para imprensa, que tem um papel significativo no sucesso das vendas, porque divulga os nomes dos vencedores dos diversos concursos. A internacionalização da Feira de Frankfurt se deve em grande medida à criação de um espaço para a imprensa.

No Festival de Cannes, por exemplo, um dos maiores festivais de cinema, a obtenção de um prêmio tem repercussão no tocante ao valor simbólico, mas também há repercussão imediata, sob o ponto de vista comercial dos filmes: os vendedores preveem que, em caso de obtenção da Palme d'or, por exemplo, o montante pago pelo comprador aumenta automaticamente. No caso dos salões de vinho, é a importância das instalações das firmas americanas, tais como Mondavi, que contribui, fortemente, para demonstrar o questionamento da hegemonia plurissecular da França, no âmbito dos vinhos de qualidade (Garcia Parpet, Leclerc \& Sorá, 20I5). Esses elementos mostram como as análises dessas feiras são essenciais para compreender o mercado, no sentido assumido pelos economistas, ou seja, como um mecanismo abstrato, no qual oferta e demanda se confrontam e se ajustam por meio da flutuação dos preços.

Como menciona Raymonde Moulin (I992) a respeito da arte contemporânea, as praças de mercado internacionais não são isoladas, sendo complementares entre si e formadoras de ciclos e circuitos mercantis. Elas se inscrevem em 
um sistema policêntrico, no qual algumas são mais ou menos centrais do que outras. Localizadas principalmente na Europa e nos EUA, regiões de produção e de aquisição dominantes, vêm se desenvolvendo cada vez mais em países emergentes, especialmente na Ásia. Os profissionais seguem esses circuitos anuais e cíclicos das praças de mercado internacionais e os utilizam de maneira diferenciada. No caso do cinema, por exemplo, algumas praças de mercado preparam outras; Rotterdam no começo do ano, e Berlim e Cannes na primavera do hemisfério Norte. Alguns são mercados de liquidações, como o de Toronto, no fim do ano, ou especializados, como o de Hong Kong.

O fato de participar desses salões de exposição, assim como o lugar ocupado nesses eventos, é importante. Assim como Brian Moeran (2010) menciona a respeito das feiras do livro, o texto de Valéria Sinischalci (2013) a propósito do salão internacional de Slow food, em Milão, mostra a importância dos lugares em que os produtores expõem no decorrer dessas concentrações. Assim, um grupo de produtores de bens em via de desaparecimento ficou contrariado ao constatar que a distribuição de lugares estava sendo modificada de um ano para o outro, e que seu desempenho sofreria com esse deslocamento do centro da feira, localização que, pela proximidade da imprensa, os vinha beneficiando em anos anteriores, e reivindicava voltar à posição anterior. ${ }^{5}$

Constituindo plataformas de observação e lugar de competição, as praças de mercado internacionais permitem aos agentes de diferentes campos nacionais elaborar novas estratégias coletivas e individuais. A frequência a feiras propicia socialização profissional. Os indivíduos procuram outras estratégias publicitárias, e outras maneiras de fazer transações, em particular porque não é na própria feira que se concluem negócios. Assim, Havens (2006) e Moran (2009) notaram que a integração, no meio da distribuição internacional de produções para televisão, demora vários anos para se constituir. Vários autores destacam também a importância das relações diretas entre vendedores e compradores, contrariando a ideia de que, à medida que se entra em "negócios importantes", as relações sociais personalizadas se diluem, necessariamente.

Da mesma forma, as plataformas digitais, praças de mercado sui generis, que não precisam de tijolo e cimento para ser erguidas, ${ }^{6}$ sem comissários nem presença física dos participantes, podem instalar-se com investimento mínimo e são seguramente criadoras de valor, como veremos adiante. Elas constituem locais de concentração da oferta e da demanda, que ficam a meio caminho entre firma e praça de mercado, reduzem o que os economistas chamam de custos de transação (Williamson, I989) e permitem investimento menor do ponto de vista da start-up.

Como praças de mercado, plataformas sincronizam atores independentes, prestando serviços que podem ser virtuais ou não e, ao mesmo tempo, tipificar consumidores e seu comportamento; e assim, como firmas, elas se apoiam em uma estrutura centralizada para extrair uma mais-valia significa- 
tiva. Mediante dispositivos que utilizam algoritmos, elas têm capacidade de coordenar dados a respeito de categorias de usuários os mais diversos e díspares (dados sobre perfil pessoal, localização, hábitos de consumo etc.), e de captar o trabalho, geralmente não remunerado, invisível e muitas vezes de natureza lúdica, dos utilizadores das redes sociais, ou de mercados, como Uber ou Airbnb. Na origem do funcionamento das plataformas, segundo Casilli (2018), há uma força de trabalho que não é reconhecida e que se ignora enquanto tal, e ignora também que está na base da produção de valor. Assim, como menciona esse autor, as redes sociais valem-se de contribuições voluntárias e de metadados dos seus usuários, que podem ser valorizados por essas plataformas por meio da sua revenda, junto a sistemas de leilões publicitários, a corretores de dados ou mesmo a Estados preocupados em vigiar sua população.?

\section{PRAÇAS DE MERCADO E DIFERENCIAÇÃO SOCIAL}

As praças de mercado são geralmente concorrentes com outras institucionalizações de troca, mercantil ou não (cooperativas, comércio estabelecido, grande distribuição, centrais de abastecimento etc.). São o resultado de compromissos entre lógicas, interesses e modelos científicos distintos, até antagonistas, de legislações estatais, de autoridades municipais e de tecnologias, que podem beneficiar, de maneira diferencial, produtores, comerciantes estabelecidos, intermediários etc., ou seja, podem favorecer ou não certas categorias sociais. Raramente suas modalidades são neutras para as trocas mercantis a que se vinculam.

As feiras do Brejo da Paraíba, no Nordeste do Brasil (Garcia Parpet, I983), constituem um bom exemplo para colocar em evidência a incidência da institucionalização específica das feiras sobre a reprodução econômica e social das diferentes categorias sociais. Nessa região existiam, no final do século XX, grandes propriedades produzindo cana-de-açúcar e criando gado, e um campesinato dotado de pouca terra, sempre ameaçado pela extensão de fazendas de gado (Garcia Jr., I990). Nessas feiras, era possível aos pequenos produtores retalhar produtos do seu roçado, tais como farinha de mandioca, feijão, milho e frutas. Essa venda ao retalho, além de trazer para esses camponeses renda maior do que se tivessem vendido em grosso a comerciantes, também os familiarizava com a manipulação do dinheiro e evolução dos preços. Em paralelo, essa venda lhes permitia fazer, no mesmo dia, o abastecimento da casa, deixando mais tempo para trabalhar no roçado. ${ }^{8} \mathrm{~A}$ articulação dos dias de feira, em um circuito de feiras, possibilitava aos agricultores tornar-se pequenos intermediários: podiam comprar produtos (alimentícios ou não) em uma feira de atacado e percorrer outras feiras durante a semana, para os retalhar junto à população local, conservando alguns dias da semana para trabalhar no roçado. A renda assim obtida os livrava da necessidade de vender sua força de trabalho nas grandes propriedades, no período de entressafra, opção considerada a pior pos- 
sível. Em alguns casos, além de os proteger dessa venda de força de trabalho, a combinação de roçado e do "negócio", termo usado para designar essa atividade, dava-lhes possibilidades de comprar terra e, portanto, de se "encampesinar". Essa renda complementar à do produto do roçado era muito importante, e quando houve boatos, a respeito de uma decisão por parte das autoridades locais, de colocar as feiras dos diferentes municípios contíguos em um só dia, a reação por parte dos pequenos produtores foi expressiva. O dia da feira era também importante para facilitar a participação dos trabalhadores residentes nos engenhos e, se não houvesse feira no sábado ou no domingo, seriam obrigados a comprar no barracão do engenho, por preços muito mais altos. Evocando o passado, os produtores mencionavam também a passagem do uso da cuia (medida barata de latão) para medição dos produtos vendidos ao retalho para o uso da balança, instrumento que requeria certo investimento monetário, o que impedia os mais desprovidos de vender na feira, troca que esteve na origem da chamada revolta do quebra-quilo, em finais do século XIX (Almeida, I957). Pelas observações anteriores, poder-se-ia pensar que essa ocorrência de efeitos sociais palpáveis em praças de mercado só poderia surgir em locais periféricos ao sistema capitalista. A análise do funcionamento das plataformas digitais, que estão na ponta da modernidade do mundo atual, entretanto, não apresenta resultados menos significativos, como veremos adiante.

\section{PLATAFORMAS DIGITAIS: DESESTRUTURAÇÃO DE ESPAÇOS ECONÔMICOS E DESCONSTRUÇÃO DO “TRABALHO DECENTE”}

As plataformas digitais têm por característica agrupar ofertantes e demandantes de produtos ou de serviços sem que estejam fisicamente presentes, o que poderia levar a pensar que se trata de uma situação perfeitamente neutra, de ponto de vista dos agentes sociais. Por um lado, como analisa Paul Belleflamme (20I7), elas modificam o funcionamento de um grande número de setores, como transporte, restauração, entregas, emprego on demand, setor bancário. O autor recapitula as vantagens dessa nova forma de business. A escolha de organização em plataformas tem consequências importantes no nível dos custos, da qualidade, dos preços e das consequências que podem se transformar em vantagens concorrenciais, em relação às firmas já instaladas. Essas empresas nada produzem e contentam-se em estabelecer o contato entre produtores e consumidores, colocando assim em xeque a teoria clássica da firma (Coase, 1937). Elas têm uma estrutura de custos completamente diferente das firmas convencionais. Além disso, essas diferenças de custo são muitas vezes ampliadas, pelo fato de as novas firmas escaparem, por um tempo, das regulações às quais estão submetidas as firmas já existentes. A organização em plataforma também tem implicações em termos de qualidade dos produtos e serviços oferecidos aos consumidores. Nada produzindo, elas são mais flexíveis que as firmas convencionais (que fizeram uma escolha de produção e o investimento necessário) e 
podem, portanto, se concentrar sobre os produtos e serviços que correspondam ao gosto do consumidor, adaptando-se, se for necessário.

Por outro lado, com o desenvolvimento das plataformas, assiste-se a uma desconstrução simultânea do mercado de trabalho tal como institucionalizado no capitalismo do século XX e que, atribuindo garantias sociais aos trabalhadores e proteção frente a doenças, invalidez ou garantindo a aposentadoria, estava na origem de uma certa coesão social, permitindo mesmo que se falasse em sociedade salarial (Castel, I995). O relatório da Organização Internacional do Trabalho (OIT), de acordo com Berg et al. (2018: XV), considera que a emergência de plataformas de trabalho digital on line é uma das maiores transformações no mundo do trabalho, nas ultimas décadas, indo contra o "trabalho decente", norma a ser respeitada no universo quotidiano, que compreende um "trabalho adequadamente remunerado, exercido em condições de liberdade, equidade e segurança, capaz de garantir uma vida digna". Da mesma maneira, a respeito da Europa, Vendramin e Valenduc (20I6) chamam atenção para a economia das plataformas, que se afasta de uma maneira inquietante do quadro-padrão do trabalho remunerado e, se por um lado, as plataformas que se dedicam ao uso regular de serviços 'externalizados' devem respeitar os preceitos legislativos, no que diz respeito ao direito comercial, à proteção dos consumidores, ao código civil e à proteção dos dados, não existem quadros legais, coletivamente definidos, que enquadrem a externalização aberta do trabalho no mundo empresarial. O trabalhador age como se fosse independente, e o conjunto de condições que o afetam (remuneração, condições de trabalho, propriedade intelectual etc.) é, em regra, determinado pela plataforma, de tal maneira que Huws (2003) desenvolveu o conceito de cybertariado (cyberproletariado), para designar esse contingente de mão de obra. Se as plataformas favorecem a eclosão de pequenas empresas e dão a um grande número de indivíduos a possibilidade de completar sua renda em condições muito flexíveis, esse modelo favorece, por outro lado, a generalização da economia dos bicos e biscates, atividades reduzidas a tarefas banais, em inglês gig economy. Com uma retórica de libertação do trabalho, por "não ter chefe, poder trabalhar em casa, ser dono do seu tempo, ter flexibilidade", as plataformas digitais facilitam a decomposição do trabalho em tarefas mais simples, a transformação em mercadoria dessas formas precárias, vendendo-as on demand ao boss, que procura extrair uma carga de trabalho a baixo custo, opondo-se a uma relação mais duradoura e mais protetora, caracterizada pelo contrato de trabalho assalariado.

O caso de Uber, no setor de transporte urbano, é o mais emblemático (Stefano, 20ı6), mas Deliveroo para entrega de refeições, Taskrabbit para trabalhos de limpeza e bricolagem, e Airbnb para hospedagem estão na origem de exemplos usados com frequência para designar essa nova maneira de institucionalizar o mercado de serviços pessoais. O trabalhador digital é uma figura da precarização, da desclassificação que atinge os meios criativos, assim como 
os utilizadores corriqueiros de internet e forma, cada vez mais, um proletariado numérico. E se as plataformas não levam ao desaparecimento do trabalho, mudam a proporção do trabalho implicitamente produtivo em relação ao trabalho formalmente identificável.

O crowdworking atingiu rapidamente cunho comercial, a exemplo da plataforma Mechanical Turk (www.mturk.com), da Amazon, em 2006. Trata-se de um mercado com duas vertentes. Na primeira delas, encontra-se a demanda de trabalho, na qual empresas ou indivíduos procuram mão de obra ocasional para tarefas realizáveis a distância (traduções, transcrições etc.). Na outra vertente, encontra-se a oferta de trabalho, na qual figuram indivíduos prontos a vender sua força de trabalho para tarefas intelectuais de curta duração, que funciona como em um leilão, em escala mundial.

O império crescente das plataformas informáticas, para regular contratos de diferentes tipos de serviços, transforma as empresas em mecanismos de coordenação de atores sociais que, de fato, operam uma marginalização, para não dizer uma denegação da força de trabalho efetivamente empregada (Casilli, 20I9). Fato notável é que as plataformas são um tipo de praça de mercado que, contrariamente às praças tradicionais, como a estudada por De La Pradelle (I996) ou Emmanuelle Lallement (2010), não implicam relações pessoais, a ponto de as exigências que têm a ver com a realização do trabalho não poder ser expressas, o que complica a vida dos trabalhadores, que veem atos recusados como válidos sem saber por quê. A ambiguidade em torno do trabalho fornecido é grande, a exemplo do caso do Huffington Post, que realiza jornalismo contributivo gratuito, e no qual somente $20 \%$ dos artigos provêm de trabalho de jornalistas remunerados. O jornal, que funcionava com nove mil bloggers, foi vendido à America On Line por 3 I 5 milhões de dólares, o que motivou a reação dos bloggers, que contribuíam gratuitamente para o funcionamento do jornal, desde sua fundação em 2005. Esses trabalhadores fizeram greve e entraram na justiça; tratava-se de um trabalho para uma causa que, de repente, era apropriada como trabalho gratuito (Simonet, 20I8). Certos autores, como Antonio Casilli (2017), mencionam "sumiço" ou denegação da força de trabalho. E, se os trabalhadores assalariados, com garantias sociais, tendem a desaparecer, as firmas tradicionais que os utilizam são também progressivamente excluídas do mercado. Por exemplo, no Booking, a cotação dos utilizadores fica mais em evidência do que as qualificações atribuídas pelas associações profissionais do turismo, que concedem notas ou estrelas aos hotéis a partir de um trabalho de avaliação (Pasquier, 20I4).

As plataformas digitais estão na origem de uma dinâmica de disparidades globais. Apoiando-se em Marc Graham et al. (20I7), Casilli (20I7) mostra que, em nível mundial, a demanda dos bens é mais concentrada nos EUA e na Europa, quando a oferta é, geograficamente, mais difusa, o que o leva a afirmar que, de certa maneira, haveria uma reprodução da situação colonial devida às condições de trabalho existentes. Graham et al. (20I7) mostram que essa gig 
economy provém largamente da Índia e das Filipinas, seguindo em direção aos EUA, Austrália, Canadá e Inglaterra. A perda de poder de barganha e a insegurança do trabalho são intensificadas por uma opacidade da cadeia de extração da mais-valia em nível global, na qual os usuários ignoram para quem eles trabalham e não têm referências a respeito das condições de remuneração e de proteção. No survey realizado pela OIT, a percepção dos trabalhadores é de que se paga pouco, além do fato de que em certos países não se paga em dinheiro, mas em papéis, como vouchers, acabando com a liquidez da remuneração. Além do mais, os trabalhadores têm que pagar o serviço de transferência de dinheiro, pelo Paypal, por exemplo. Sobretudo em países da África, da Ásia e da América Latina, muitos crowdworkers estão em uma situação financeira precária. Percebem-se dinâmicas de exclusão social em países como a Índia, as Filipinas, Bandaglesh, Vietnam, Malásia, Nigéria e Quênia. Essa modalidade de trabalho é apresentada como a melhor (e às vezes a única), personificando o "futuro de trabalho". Entre os vários efeitos dessa concentração da demanda em países como os EUA e as nações europeias, Daniel Kleiner (20I6) descreve as estratégias das plataformas que tornam homogêneas não somente as mercadorias, mas as normas exigidas dos participantes das trocas. Esses diversos exemplos mostram claramente que uma determinada institutionalização das trocas, como a das plataformas, tem incidência significativa sobre os termos das trocas e o enriquecimento ou empobrecimento dos parceiros envolvidos, assim como sobre a reestruturação dos campos de atividade.

\section{CONCLUSÃo}

Neste artigo, demonstramos que o corpo conceitual e os questionamentos teóricos propostos por Karl Polanyi, em sua passagem pela Grã-Bretanha e pelos EUA, durante a Segunda Guerra Mundial e nas décadas seguintes, continuam válidos para abrir caminhos novos de investigação em ciências sociais e para compreender os significados e as condições novas de funcionamento da economia, que têm sido apresentados como globalização (ou mundialização dos mercados). Entre os anos I940 e I960, o desafio enfrentado por Karl Polanyi foi objetivar modalidades de trocas mercantis e não mercantis que haviam sido objeto de estudo de várias disciplinas, como a antropologia social, a sociologia, a história antiga, para evidenciar que a tendência a realizar trocas mercantis não estava inscrita na natureza humana, como afirmam os economistas mainstream, mas estava associada a instituições que fixavam as tonalidades e as condições do intercâmbio. A gênese do sistema capitalista é um processo particular da Europa do século XVIII, estudada como momento histórico de "grande transformação". As distinções conceituais produzidas nas controvérsias científicas, especificadas a partir das diferenças entre os conceitos de mercado -, operado pelos economistas, supondo o encontro virtual de agentes possuidores de bens e serviços dispostos a trocá-los por moeda, em poder de agentes despojados 
daqueles bens e serviços - e praças de mercado, locais concretos onde trocas mercantis são realizadas, permitem ir muito além das evidências apresentadas em estudos antropológicos, sociológicos ou históricos.

Se a existência da praça de mercado não é um indício de funcionamento do sistema de mercado, sua análise não deixa de ser um elemento essencial para estudo do sistema capitalista atual, especialmente no que toca à valorização simbólica de bens e de serviços e à diferenciação social que pode engendrar . $\mathrm{O}$ sistema de mercados formadores de preço não é único nem homogêneo, nem está dado uma vez por todas; por exemplo, certas praças de mercado reforçam laços sociais, enquanto outras os diluem, e podem ser mais ou menos favoráveis a certas categorias sociais. Entender sua dinâmica exige estar muito atento às suas formas de institucionalização para os agentes sociais, que atuam como protagonistas, para as categorias de pensamento e ação de que lançam mão, e com que conseguem graus variáveis de legitimidade. Sua análise vem se somando ou se combinando com as regulamentações, que podem constituir ou não barreiras de entrada nos mercados, tanto quanto os acordos internacionais de profundas repercussões, em intercâmbios no interior das nações, como vêm assinalando, por exemplo, os estudos de Pierre Bourdieu (I997b), Neil Fligstein (200I) e François Denord e Antoine Schwartz (2009). No caso das plataformas digitais, por exemplo, seria interessante analisar como as lutas travadas para requalificar o trabalho e sua implicações sobre o direito social e instituições de proteção à saúde, aquelas voltadas para aposentadoria e pensões. Os debates suscitados com os poderes públicos sobre tributação dos ganhos auferidos pelas plataformas, que, por sua vez, adquirem um caráter específico devido ao gigantismo e internacionalização de algumas delas (Google, Facebook, Amazon etc.) podem constituir outro objeto de investigação. Longa é portanto a lista dos potenciais usos heurísticos do reconhecimento da peculiaridade de praça de mercado como conceito, assim como de seu emprego, para elaborar teoria e proceder à análise empírica dos fatos econômicos.

Recebido em oI/06/2020 | Revisto em 21/07/2020 | Aprovado em 20/I0/2020 
Marie France Garcia Parpet é antropóloga formado pelo Museu Nacional; foi professora no IFCS/UFRJ e pesquisadora no Instituto Nacional de Pesquisa Agronômica. Trabalha em torno da sociologia da economia e em especial dos mercados no Brasil e na França. Atualmente é pesquisadora associada no Centre de Sociologie Européenne/EHESS. Publicou "La construction sociale d'un marché parfait: le marché au cadran de Fontaines en Sologne, Le marché de l'excellence: les grands crus à l'épreuve de la mondialisation", "Marché, rationalité et faits sociaux totaux: Pierre Bourdieu et l'économie”. 


\section{NOTAS}

I Agradeço a Rodrigo Santos e aos pareceristas da revista pelas sugestões preciosas, a Afrânio Raul Garcia Jr., por sua leitura meticulosa e sugestões.

2 A literatura a respeito das plataformas digitais foi recolhida numa revisão específica, a respeito desse tema, realizada com Camila Belivaqua e publicada numa coletânea de textos coordenada por José Roberto Afonso, Revolução 4.0 (Garcia Parpet \& Belivaqua, 2020).

3 "Nenhuma sociedade poderia suportar, mesmo por tempo breve, os efeitos de um tal sistema fundado em ficções grosseiras, se a substância humana e natural, assim como sua organização comercial, não fosse protegida contra a destruição desse moinho satânico" (Polanyi, I983: I08-I09).

4 Por exemplo, a feira dos vinhos mais popular de Chinon foi renomeada como salão, termo mais nobre, quando os organizadores dessa denominaçao de origem passaram a ser produtores para a elite (Garcia Parpet, 2005).

5 É interessante notar que na França a extensão de stands situada na entrada do salão de exposição de vinho é chamada de quadrado de ouro (Garcia Parpet, 2009).

6 O que se pode perceber como uma certa desmaterializaçao não impede que essas praças de mercado sejam objeto de regulamentos e lutas, no que diz respeito à tributação e à qualidade ética dos produtos.

7 Patricia Vendramin e Gérard Valenduc (20I6) nomeiam os agentes desse processo "prossumidores", porque são ao mesmo tempo produtores e consumidores. O prossumidor realiza trabalho, na maior parte das vezes não remunerado, que consiste em fornecer dados e serviços, antes fornecidos pelos assalariados, como, por exemplo, a avaliação de qualidade de um serviço ou de um produto por um usuário. Essa evolução levou Ursula Huws (2003) a considerar que as tecnologias de informação e comunicação (TIC), fornecendo novas ferramentas que permitem estender e diversificar o trabalho não remunerado, contribuem para reorganizar a divisão social do trabalho.

8 Em Pernambuco, Moacir Palmeira (20I4), que analisa por meio da feira as mudanças sociais na área canavieira, observa essa oportunidade de vender para os trabalhadores e complementar sua renda. 


\section{REFERÊNCIAS BIBLIOGRÁFICAS}

Albinsson, Paul \& Perera Yasanti. (2012). Alternative market places in the 2ist Century: building community through sharing events, Journal of Consumer Behavior, II, p. 303-3I5.

Almeida, Horacio de. (I957). O Brejo de Areia. Rio de Janeiro: Ministério da Educação e Cultura.Appadurai, Arjun (org.). (I986). The social life of things: commodities in cultural perspective. Cambridge: Cambridge University Press, p. 64-9I.

Belleflamme, Paul. (2017). Les plateformes de l'économie collaboratives et enjeux. In: Drecop, Alain. La consommation collaborative: enjeux et défis de la nouvelle société du partage. [S.1.]: De Boeck.

Berg, Janine et al. (2018). Digital labour platforms and the future of work: toward decent work in the online world. [S.l.]: International Labour Office.

Bohannan, Paul \& Dalton, Georges. (I962). Markets in Africa. Evaston: Northwestern University Press.

Boltanski, Luc \& Esquerre, Arnaud. (2017). Enrichissement. Paris: Gallimard.

Bourdieu, Pierre. (I977a). La production de la croyance: contribution à une économie des biens symboliques. Actes de la Recherche en Sciences Sociales, I3, p. 3-43.

Bourdieu, Pierre. (I997b). Le champ économique. Actes de la Recherche en Sciences Sociales, II9, p. 48-66.

Bourdieu, Pierre. (1975). Le couturier et sa griffe: contribution à une théorie de la magie. Actes de la Recherche en Sciences Sociales, I, p.7-36.

Bousquet, Georges Henry. (I969). Un système de ventes publiques curieux et important: les veilings au Pays Bas. Revue d'Économie Politique, 79/4, p. 8I8-82I.

Brisset, Karen \& Naegelen, Florence. (2008). Enchères en ligne et E-commerce. Reuue Française d'Économie, 23/I, p. I65-20I.

Bueno, Maria Lucia. (200I). Artes plásticas no século XX: modernidade e globalização. 2 ed. Campinas: Editora da Unicamp/Imprensa Oficial/Fapesp.

Callon, Michel. (1998). The laws of the market. Hoboken: Wiley-Blackwell. 
Casilli, Antonio. (2019). Is there a global digital labor culture? Marginalization of work, global inequalities, and coloniality. Archive Ouverte en Sciences de l'Homme et de la Société. Disponível em: <https://halshs.archives-ouvertes.

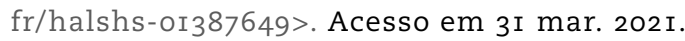

Casilli, Antonio. (2018). La plateformisation comme mise au travail des usagers. Digital labour et nouvelles inégalités planétaires. In: Corat, Benjamin et al. Vers une république des biens communs. Paris: Les liens qui libèrent, p. $4 \mathrm{I}-56$.

Casilli, Antonio. (2017). Digital labor studies go global: toward a digital decolonial turn. International Journal of Communication, II, 3934-3954.

Castel, Robert. (1995). La métamorphose de la question sociale. Paris: Fayard.

Coase, Ronald. (1937). The nature of the firm? Paris: Economica.

Cook, Scott. (1966). The obsolete anti-market mentality: a critique of the substantive approach to the economic antropology. American Antropologist, 68, p. 323-345.

Denord François \& Schwartz, Antoine. (2009). L'Europe sociale n'aura pas lieu. Paris: Raisons d'agir.

Fligstein, Neil. (200I). The architecture of markets. Princeton: Princeton and Oxford.

Garcia Jr., Afrânio. (I990). Terra de trabalho. Rio de Janeiro: Paz e Terra.

Garcia Parpet, Marie France. (2009). Le marché de l'excellence, les grands crus à l'épreuve de la mondialisation, Paris: Seuil. Garcia Parpet, Marie France. (2005). Le salon des vins de Loire: convivialité et vocation internationale. Ethnologie Française, 35/I, p. 63-72.

Garcia Parpet, Marie France. (2003). A construção social de um mercado perfeito: o caso de Fontaines em Sologne. Estudos, Sociedades e Agricultura, 25/2.

Garcia Parpet, Marie France. (1996). Représentations savantes et pratiques marchandes. Genèses, 25.

Garcia Parpet, Marie France. (1983). Negócio e campesinato: uma estratégia de reprodução social. Boletim do $\mathrm{Mu}$ seu Nacional, 45. 
Garcia Parpet Marie France \& Belivaqua, Camila. (2020). As novas economias digitais: impacto sobre o trabalho e "gig" economy. In: Afonso, José Roberto. Trabalho 4.0. São Paulo: Almedina Brasil.

Garcia Parpet, Marie France; Leclerc, Romain \& Sorá, Gustavo. (20I5). Salons, foires internationales et mondialisation des biens symboliques. In: Siméant, Johanna (dir.). Guide de l'enquête globale en sciences sociales. Paris: Éditions du CNRS.

Graham, Marc et al. (2017). Digital labour and development: impacts of global digital labour platforms and the gig economy on worker livelihoods. Transfer, European Review of Labor and Research, 23/2, p. 135-162.

Hassoun, Jean-Pierre. (2000a). Trois interactions hétérodoxes sur les marchés à la criée du Matif. Rationalité locale et rationalité globale. Politix, 52, p. 99-II9.

Hassoun Jean-Pierre. (200ob). Le surnom et ses usages sur les marchés à la criée du Matif. Controle social, fluidité relationnelle et représentations collectives. Genèses, 4I, p. 5-40.

Havens, Timothy. (2006). Global television marketplace. London: British Film Institute.

Huws, Ursula. (2016). Logged labour: a new paradigm of work organisation? Work Organisation, Labour \& Globalisation, Io/I, p. 7-26.

Huws, Ursula. (2003). The making of a cybertariat: virtual work in a real world. New York, Monthly Review Press.

Kleiner, Daniel. (2016). Mr. Peel goes to cyberspace: resisting digital colonization. Paper presented at the Digital Bauhaus Summit 20I6: Luxury Communism, Weimer, Germany.

Kopytoff, Igor. (I986). The cultural biography of things: commoditization as process in The social life of things: commodities in cultural perspective. In: Appadurai, Arjun (org.). The social life of things: commodities in cultural perspective. Cambridge: Cambridge University Press, p. 64-9I.

Krohn, Lilian. (2017). Beber, fazer, vender: formação do mercado de cerveja "artesanal" no Brasil. Dissertação de Mestrado. PPGS/Universidade de São Paulo. 
Lallement, Emmanuelle. (2010). La ville marchande: enquête à Barbès. Paris: Teraèdre.

Leal, Natacha. (2008). É de agronegócio. Circuitos relações e trocas entre peões de rodeio e tratadores de gado em feira de pecuária. Dissertação de Mestrado. PPGAS/Universidade de São Paulo.

MacKenzie, Donald; Muniesa, Fabian \& Siu, Lucia (orgs.). (2007). Do economists make markets? Princeton: Princeton University Press.

Malinowski, Bronislaw et al. (1984). The economics of a Mexican market system. Ethics, 94/4, p. 72I-723.

Moeran, Brian. (2010). The book fair as a tournament of values. Journal of the Royal Anthropological Institute, I6/I, p. I38-I54.

Moran, Albert. (2009). New flows in global TV. Bristol/Chicago: Inellect Books/The Mill/The University of Chicago Press.

Moulin, Raymonde. (1992). L'artiste, l'institution et le marché. Paris: Flammarion.

Müller, Lucia Helena. (2006). Mercado exemplar: um estudo antropológico sobre a Bolsa de Valores. Porto Alegre: Zouk.

Muniesa, Fabian. (2007). Market technologies and the pragmatics of prices. Economy and Society, 36/3, p. 377-395.

Palmeira, Moacir. (20I4). Feira e mudança econômica. Vibrant: Virtual Brazilian Anthropology, I I/I, p. 324-36o.

Paranthoën, Jean-Baptiste. (2015). L'incursion des scientifiques dans l'organisation des marchés agricoles: la promotion des circuits courts. Politix, 28/I I I.

Parsons, Talcott \& Smelser, Neil J. (I956). Economy and society. Glencoe, Illinois: The Free Press.

Pasquier, Daniel .(2014). Les jugements profanes en ligne sous le regard des sciences sociales, Réseaux, I83, p. 9-26. Piault, Marc. (I97I). Cycle de marchés et 'espaces' sociopolitiques. In: Meillassoux, Claude. The development of indigenous trade and markets in Africa. Oxford: Oxford University Press.

Picanço, Monise Fernandes. (2018). Caleidoscópio da valoração. A HSM Expomanagement e o processo de constituição de 
seus produtos. Tese de Doutorado. PPGS/Universidade de São Paulo.

Polanyi, Karl. (1983) [1944]. The great transformation. Paris: Gallimard.

Polanyi, Karl. (I968) [1947]. Our obsolete market mentality. In: Dalton, Georges (ed.). Primitive archair and modern societies, essays of Karl Polanyi. New York: Anchor books.

Polanyi, Karl. (1957). Trade and market in the early empires: economies in history and theory. Glencoe: The Free Press.

Pradelle, Michèle de la. (1996). Les vendredis de Carpentras. Paris: Fayard.

Pulman, Bertrand. (20I9). Salons: rencontres et surprises. Paris: Dunod.

Quemin, Alain. (1994). L'espace des objets. Expertises et enchères à Drouot-Nord. Genèses, <https://www.persee. fr/issue/genes_II55-32I9_I994_num_I7_I?sectionId=gen es_II55-32I9_I994_num_I7_I_I26I > I7, p. 52-7I.

Rabossi, Fernando. (2004). Nas ruas de Ciudad del Este: vidas $e$ vendas num mercado de fronteira. Tese de Doutorado. PPGAS/Universidade Federal do Rio de Janeiro.

Simonet, Maud. (20I8). Travail gratuit: la nouvelle exploitation? Paris: Textuel.

Siniscalchi, Valeria. (2013). Slow versus food. Terrain, 6o, p. I32-I 47 .

Skinner, Georges W. (1964). Marketing and social structure in rural China, part I. The Journal of Asian Studies, 24/I, p. 3-43.

Stefano, Valerio. (2016). The rise of the "just-in-time workforce": on-demand work, crowdwork and labour protection in the "gig-economy". Geneva: ILO. (Conditions of Work and Employment Series, 7I).

Steiner, Philippe. (2010). La transplantation d'organes. Un commerce nouveau entre les êtres humains. Paris: Gallimard. Vaudois, Jean. (I980). Le développement des marchés au cadran dans la région du Nord. Études Rurales, 78/80, p. II3-I33.

Vaudois, Jean. (1985). Marchés physiques et organisation du marché des fruits et légumes frais dans les pays de la CEE. Le rôle des enchères dégressives. Economie Rurale, I65, p. I2-I7. 
I46

Vendramin Patricia \& Valenduc, Gérard. (2016). Le travail virtuel. Nouvelles formes d'emploi et de travail dans l'économie digitale. Disponível em: <http://hdl.handle.net/2078.I/I742 24>. Acesso 3I mar. 202I.

Williamson, Olivier E. (1989). <https://www.sciencedirect. com/science/article/pii/SI573448X890I006X>. Transaction cost economics - handbook of industrial organization. Amsterdã: Elsevier. 


\section{Palavras-chave \\ Mercado, praça de mercado; sistema de mercados; institucionalização; Karl Polanyi, salões de exposição, plataformas digitais.}

Keywords

Market;

marketplace;

system of price-forming market; institutionalization;

Karl Polanyi;

fair; digital platform.
MERCADOS E PRAÇAS DE MERCADO: KARL POLANYI E O CAPITALISMO CONTEMPORÂNEO

\author{
Resumo \\ Explorando as distinções conceituais entre mercado, siste-
} ma de mercados formadores de preço e praça de mercado, concebidas por Karl Polanyi, o artigo mostra a pertinência dessas diferenças para a análise do capitalismo contemporâneo, ao focalizar a caracterização e os efeitos específicos de praças de mercado da atualidade. Evoca a contribuição de Polanyi para repensar o conceito de mercado tal como referido na literatura econômica e especificar a historicidade dos mercados, sobretudo do sistema de mercados formadores de preço (equivalente de sistema capitalista), opondo esses conceitos a praças de mercado. Recorre a trabalhos etnográficos e/ou sociológicos, sobre praças de mercado contemporâneas, verificando que elas existem nas configurações atuais das trocas mercantis e podem criar valor simbólico e material, estando na origem de processos de diferenciação social, intensificados, por exemplo, no caso das plataformas digitais.

\section{MARKETS AND MARKET PLACES: KARL POLANYI AND CONTEMPORARY CAPITALISM}

\section{Abstract}

This article explores the conceptual distinction between market, system of price-making market and marketplace created by Karl Polanyi and shows the relevance of this differences for the analysis of the contemporary capitalism focusing on the characterization and specific effects of actual marketplaces. It evokes Polanyi's contribution to rethink the concept of market as the economic literature refers to specify the historicity of the markets, especially the system of price-forming market (equivalent to the capitalist system), opposing these concepts to marketplaces. It resorts to ethnographic and/or sociological works on marketplaces in the contemporary world. It supposes that marketplaces exist in the current configuration of market exchange, may create value symbolic, and material, as well as are at the origin of processes of social differenciation, intensified, for example, in the case of digital platforms. 